\title{
ADSORPSI ZAT WARNA TEKSTIL REMAZOL BRILLIANT BLUE OLEH LIMBAH CANANG DAUN KELAPA
}

\author{
S. R. Mustikawati*, I N. Simpen, dan O. Ratnayani \\ Program Studi Kimia, Fakultas MIPA, Universitas Udayana, Bukit Jimbaran, Bali \\ *Email: ramustika11@gmail.com
}

\begin{abstract}
ABSTRAK
Telah dilakukan penelitian adsorpsi zat warna tekstil Remazol Brilliant Blue dengan 2 macam adsorben yaitu adsorben daun kelapa dan adsorben daun kelapa terdelignifikasi (selulosa) yang berasal dari limbah canang daun kelapa. Dalam penelitian ini dilakukan tiga tahap, yaitu preparasi, optimasi, dan karakterisasi. Preparasi untuk mendapatkan adsorben daun kelapa dan selulosa, dan kemudian optimasi dilakukan untuk mengetahui kondisi optimum kedua adsorben dengan variasi massa adsorben, waktu kontak, dan $\mathrm{pH}$ larutan. Terakhir, karakterisasi dilakukan untuk mengetahui luas permukaan adsorben secara Methylene Blue method, jumlah situs aktif kedua adsorben dengan metode titrasi asam-basa, serta gugus fungsi dengan Fourier transform infrared (FTIR). Pada optimasi, diketahui bahwa kondisi optimum kedua adsorben adalah waktu optimum menit ke 15 dengan massa optimum adsorben 0,1 gram dan $\mathrm{pH} 4$, dengan jumlah adsorbat yang teradsorpsi 10,6 mg/g untuk adsorben daun kelapa dan $10,7 \mathrm{mg} / \mathrm{g}$ untuk adsorben daun kelapa terdelignifikasi. Pada penentuan luas permukaan dihasilkan berturut-turut adsorben daun kelapa dan daun kelapa terlignifikasi $34,796 \mathrm{~m}^{2} / \mathrm{g}$ dan $31,867 \mathrm{~m}^{2} / \mathrm{g}$, sedangkan jumlah situs aktif adalah 29,7258 x $10^{20}$ molekul /gram dan 28,0522x $10^{20}$ molekul/gram. Spektra FTIR menunjukan bahwa daun kelapa terdelignifikasi memiliki gugus OH yang sama dengan selulosa murni.
\end{abstract}

Kata Kunci: adsorpsi, delignifikasi, limbah canang, Remazol Brillian Blue

\begin{abstract}
Adsorption of textile dyes Remazol Brilliant Blue has been done by using 2 kinds of adsorbents such as coconut leaf and delignificated coconut leaf (cellulose) obtained from coconut leaf wastes. In this research, there were three stages applied: preparation, optimizing and characterization. Preparation was carried out for producing the adsorbents, and then the optimizing process for having the optimum conditions of the two adsorbents with the variations of adsorbent mass, contact time and $\mathrm{pH}$. Finally, the characterization was performed by calculating the surface area of the adsorbents using Methylene Blue method, as well as calculating the number of active sites of both adsorbents with acid-base titration method and functional groups determination by Fourir transform infrared (FTIR). In the optimization process it was found that the optimum conditions of the two adsorbents were at 15 minutes, using 0.1 gram of adsorbent and at $\mathrm{pH} 4$, which resulted in the adsorption of $10.6 \mathrm{mg} / \mathrm{g}$ of the dyes for the coconut leaf and $10.7 \mathrm{mg} / \mathrm{g}$ for the delignificated coconut leaf. The number of surface area for the coconut leaf and delignified coconut leaf adsorbents were respectively $34.796 \mathrm{~m}^{2} / \mathrm{g}$ and $31.867 \mathrm{~m}^{2} / \mathrm{g}$ as well as the number of active sites were $29.2994 \times 10^{20}$ molecules/gram and $27.2724 \times 10^{20}$ molecules/gram. The FTIR spectra showed that the delignificated coconut leaves had the same $\mathrm{OH}$ group with pure cellulose.
\end{abstract}

Keywords: adsorption, delignifcation, canang waste, Remazol Brilliant Blue

\section{PENDAHULUAN}

Pulau Bali dengan mayoritas beragama Hindu memanfaatkan daun kelapa untuk dibuat menjadi canang. Dalam upaya memanfaatkan kelimpahan canang, canangdapat digunakan sebagai adsorben karena terdapat kandungan selulosa sebesar
$23,83 \%$ (Thomas et al., 1998) sehingga dapat dimanfaatkan sebagai biosorben.

Potensi selulosa untuk digunakan sebagai adsorben dengan memanfatkan gugus hdroksil pada tiap unit polimernya. Untuk mendapatkan selulosa dari daun kelapa dilakukan proses delignifikasi, yaitu 
penghilangan gugus lignin dari rantai selulosanya.

Di sisi lain, dalam industri tekstil, zat warna azo Remazol Brilliant Blue merupakan salah satu zat warna yang banyak digunakan. Polutan pewarna dari industri tekstil adalah salah satu sumber pencemar yang menkontaminasi lingkungan dikarenakan setelah pewarna masuk ke dalam badan air, pewarna tersebut akan semakin stabil dan lebih sulit terurai (Forgacs et al., 2004).

Selulosa memiliki gugus aktif -OH yang mampu mengikat zat warna tekstil, dimana dalam penelitian tersebut zat warna yang digunakan adalah adalah Direct Blue 86 yang termasuk zat warna tekstil langsung (direct dye) (Windasari, 2009). Penelitian Windasari menggunakan kulit kacang tanah sebagai adsorben untuk alternatif pengolahan limbah industri tekstil karena biayanya yang relatif murah dan mudah didapatkan. Adsorben kulit kacang memiliki kapasitas adsorpsi pada $\mathrm{pH}$ optimum yaitu 6 dengan jumlah zat teradsorpsi sebesar $1,909 \mathrm{mg} / \mathrm{g}$. Konsentrasi $\mathrm{NaOH}$ optimum untuk delignifikasi kulit kacang tanah adalah $2 \mathrm{M}$ dengan jumlah zat yang teradsorpsi 3.2787 $\mathrm{mg} / \mathrm{g}$. Selisih perbedaan jumlah zat yang teradsorpsi antara kulit kacang tanah tanpa delignifikasi dengan kulit kacang tanah yang didelignifikasi sebesar $1.3467 \mathrm{mg} / \mathrm{g}$ atau 41,07 $\%$.

Dalam penelitian ini, untuk membandingkan kualitas adsorben daun kelapa dibuatlah dua variasi adsorben daun kelapa yang berbeda, yaitu daun kelapa delignifikas dan adsorben dibuat tanpa proses delignifikasi Kedua jenis adsorben ini kemudian dikarakterisasi dengan melihat kondisi optimumnya.

\section{MATERI DAN METODE}

\section{Bahan dan Peralatan}

Bahan-bahan yang digunakan pada penelitian ini adalah daun kelapa yang diperoleh dari limbah canang, $\mathrm{NaOH}$ p.a, $\mathrm{NaOCl}$ p.a, methylene blue, serbuk Remazol Brilliant Blue, kertas saring dan aquades.

Alat-alat yang digunakan dalam penelitian ini meliputi spektrofotometer FTIR, Spektrofotometri UV-Vis, pH-meter, neraca analitik, peralatan gelas (gelas beker, erlenmeyer, labu ukur, pipet volume, pipet ukur, pipet tetes dan corong kaca), pengaduk magnet dengan pemanas, termometer, desikator, oven, blender dan botol sampel.

\section{Delignifikasi}

Canang yang terkumpul kemudian dibersihkan dan dipotong-potong untuk memperbesar luas permukaan. Canang yang sudah dibersihkan kemudian dikeringkan dan dihaluskan serta diayak untuk mendapatkan serbuk daun kelapa. Sebanyak 30 gram serbuk daun kelapa hasil preparasi dimasukkan ke dalam $500 \mathrm{~mL}$ larutan $\mathrm{NaOH} 12 \%$, kemudian dipanaskan pada suhu $100^{\circ} \mathrm{C}$ selama 1 jam sambil diaduk dengan pengaduk magnet, pemanasan selanjutnya di-bleaching dengan $\mathrm{NaOCl}$. Suspensi selulosa dihidrolisis menggunakan katalis asam, kemudian didiamkan sampai 24 jam pada suhu kamar. Suspensi selanjutnya dinetralisasi dengan basa $\mathrm{NaOH} 1 \%$ dan disaring (Nurwendi, dkk., 2016).

\section{Penentuan Luas Permukaan Adsorben Secara Methylene Blue Method}

Sebanyak 0,1 gram adsorben daun kelapa dan daun kelapa dimasukkan ke dalam erlenmeyer yang berisi 20,0 mL larutan BiruMetilen 5 ppm. Larutan kemudian diaduk dengan pengaduk magnet dengan variasi waktu kontak 5, 10, 15, 20, 30, 45, 60 menit. Larutan hasil pengocokan disaring dan filtratnya dianalisis menggunakan Spektrofotometri UV-Vis.

\section{Penentuan Asam Muka dan Jumlah Situs Aktif}

Disiapkan 3 buah erlenmeyer $100 \mathrm{~mL}$, masing-masing diisi dengan 0,50 g sampel, kemudian pada tiap erlenmeyer ditambahkan 25,0 mL larutan $\mathrm{NaOH} 1 \mathrm{M}$. Campuran tersebut diaduk dengan pengaduk magnet selama 15 menit dan disaring menggunakan kertas saring. Perlakuan yang sama juga dilakukan terhadap blanko yang hanya mengandung 25,0 mL larutan $\mathrm{NaOH} 1 \mathrm{M}$. Masing-masing filtrat ditambahkan 2-3 tetes indikator phenolphtalein (pp) yang ditandai dengan munculnya warna merah muda. Filtrat tersebut dititrasi dengan larutan $\mathrm{HCl} 1 \mathrm{M}$ sampai bening (tidak berwarna). 


\section{Penentuan Gugus Fungsi}

Adsorben daun kelapa dan daun kelapa terdelignifikasi diuji menggunakan instrumentasi FTIR untuk mengetahui gugus fungsinya.

\section{Penentuan isoterm adsorpsi}

Sebanyak 4 buah erlenmeyer $100 \mathrm{~mL}$ masing-masing dimasukkan $50 \mathrm{~mL}$ larutan standar Remazol Brilliant Blue konsentrasi 50, 75, 100, dan 150 ppm dan ditambahkan sejumlah adsorben pada massa optimum. Larutan tersebut kemudian diaduk menggunakan pengaduk magnet selama waktu optimum pada suhu kamar. Setelah tercampur, larutan disaring untuk mendapatkan filtratnya, fltrat yang didapat kemudian diukur dengan menggunakan Spektrofotometri UV-Vis (Megawati dalam Purnama, 2014).

\section{Penentuan kondisi optimum adsorben}

Dengan memvariasikan massa adsorben, 0,$1 ; 0,3 ; 0,5 ;$ dan 1 gram daun kelapa dan daun kelapa terdelignifikasi ditambahkan $25 \mathrm{~mL}$ larutan Remazol Brilliant Blue 25 ppm yang telah diatur pH-nya dengan penambahan $\mathrm{HCl}$ dan $\mathrm{NaOH}$, sehingga diperoleh $\mathrm{pH}$ 2, 4, 6, 8. Campuran adsorben dan larutan Remazol Brilliant Blue kemudian diaduk dengan pengaduk magnet dengan variasi waktu kontak 5, 15, 30, 60 dan 90 menit. Setelah diaduk larutan disaring dan diukur absorbansinya dengan Spektrofotometri UV-Vis. Selanjutnya, dibuat kurva kalibrasi dengan plot antara absorbansi (y) dengan konsentrasi (x) (Handayani, 2010)

\section{HASIL DAN PEMBAHASAN}

\section{Luas Permukan Adsorben}

Luas permukaan spesifik suatu adsorben berhubungan dengan kemampuan adsorben tersebut menyerap adsorbat yang dinyatakan dengan satuan $\mathrm{m}^{2} / \mathrm{g}$. Semakin besar luas permukaan nya maka semakin banyak pula adsorbat yang terserap. Permukaan yang luas tersebut terbentuk karena banyaknya pori yang halus pada padatan (Bernasconi et al., 1995). Panjang gelombang metilen biru yang terukur dalam penelitian ini adalah $664,80 \mathrm{~nm}$ yang merupakan panjang gelombang maksimum metilen biru.

Berdasarkan perhitungan diketahui bahwa luas permukaan adsorben daun kelapa dan daun kelapa terdelignifikasi adalah 34,769 $\mathrm{m}^{2} / \mathrm{g}$ dan $31,867 \mathrm{~m}^{2} / \mathrm{g}$. Perbedaan nilai luas permukaan adsorben daun kelapa dan daun kelapa delignifikasi disebabkan karena masih adanya pengotor non-selulosa dan lignin, sehingga permukaannya tertutupi dan kemampuan menyerap metilen biru berkurang. Pengotor pada pori dapat menghambat proses adsorpsi, apabila pengotor tersebut larut maka akan memperbesar situs aktif sehingga luas permukaan akan lebih besar. Sedangkan pada adsorben daun kelapa, proses penghancuran secara fisika yaitu pemblenderan membuat luas permukaan menjadi lebih besar secara alami

\section{Asam Muka dan Jumlah Situs Aktif Adsorben}

Penentuan situs aktif adsorben bertujuan untuk mengetahui jumlah mmol situs asam yang terikat pada masing-masing adsorben setiap gramnya. Penentuan jumlah situs aktif dilakukan dengan metode titrasi asam basa dengan mereaksikan adsorben dengan basa berlebih ,yaitu $\mathrm{NaOH}$. Sisa $\mathrm{NaOH}$ yang tidak berekasi dengan adsorben dititrasi dengan $\mathrm{HCl}$, sehingga jumlah zat yang berekasi ekivalen satu dengan yang lain. Jumlah situs aktif daun kelapa dan daun kelapa terdelignifikasi adalah 29,2994 x $10^{20} \mathrm{molekul} / \mathrm{gram}$ dan $27,2724 \mathrm{x}$ $10^{20}$ molekul/gram. Jumlah situs aktif adsorben daun kelapa lebih besar daripada daun kelapa terdelignifikasi. Hal ini menjelaskan bahwa adsorben daun kelapa yang tanpa melalui proses ekstraksi memiliki situs aktif yang lebih banyak sedangkan penyebab jumlah situs aktif daun kelapa terdelignifikasi lebih rendah kemungkinan dikarenakan masih adanya pengotor dan belum sempurnanya ekstraksi. Mengetahui jumlah situs aktif sebuah adsorben dapat membantu memperkirakan sifat keasaman suatu adsorben. Apabila adsorben bersifat asam, yang artinya situs asamnya lebih banyak, maka terdapat situs asam Bronsted dan asam Lewis yang berfungsi untuk mengikat zat yang diadsorpsi (adsorbat). 
Tabel 1. Asam Muka dan Jumah Situs Aktif Adsorben

\begin{tabular}{ccccc}
\hline \multirow{2}{*}{ Titrasi } & \multicolumn{4}{c}{ Jenis Adsorben } \\
\cline { 2 - 5 } & \multicolumn{2}{c}{ Adsorben Daun Kelapa } & Adsorben Daun kelapa delignifikasi \\
\cline { 2 - 5 } & $\begin{array}{c}\text { Asam muka } \\
(\mathrm{mmol} / \mathrm{g})\end{array}$ & $\begin{array}{c}\text { Situs Asam } \\
(\text { molekul/gram })\end{array}$ & $\begin{array}{c}\text { Asam muka } \\
(\mathrm{mmol} / \mathrm{g})\end{array}$ & $\begin{array}{c}\text { Situs Asam } \\
(\mathrm{moleul} / \mathrm{gram})\end{array}$ \\
\hline I & 4,8749 & & 4,5070 & \\
II & 4,8749 & $29,7258 \times 10^{20}$ & 4,5070 & $28,0522 \times 10^{20}$ \\
II & 5,0589 & & 4,6910 & \\
\hline
\end{tabular}

\section{Gugus Fungsi Adsorben}

Hasil analisa FTIR adsorben daun kelapa pada Gambar 1, dapat dilihat adanya puncak pada bilangan gelombang $1734,01 \mathrm{~cm}^{-}$ ${ }^{1}$ yang menunjukkan adanya ikatan rangkap $\mathrm{C}=\mathrm{O}$ dan teramati puncak pada bilangan gelombang 2931,80 $\mathrm{cm}^{-1}$, yang merupakan vibrasi regangan asimetris dari ikatan $\mathrm{C}-\mathrm{H}$. Pelebaran puncak yang tejadi pada bilangan gelombang $3554,81 \mathrm{~cm}^{-1}$ yang menunjukan adanya ikatan $\mathrm{O}-\mathrm{H}$ regang yang melebar. Pelebaran puncak kemungkinan terjadi akibat adsorben masih mengandung air, yang masih tersisa dan belum menguap sempurna pada saat pengeringan. Setelah melalu proses delignifikasi, terlihat bahwa ikatan rangkap terputus menjadi ikatan tunggal yang dibuktikan pada bilangan gelombang $1365,60 \mathrm{~cm}^{-1}, 1201,65 \mathrm{~cm}^{-1}, 1080,14 \mathrm{~cm}^{-1}$. Selain itu, terjadi penguatan puncak pada bilangan gelombang 1635,64 $\mathrm{cm}^{-1}, 2098,55$ $\mathrm{cm}^{-1}, 2899,01 \mathrm{~cm}^{-1}$ dan $3805,55 \mathrm{~cm}^{-1}$. Sesuai dengan pengertian delignifikasi, yaitu proses pemutusan ikatan-ikatan dasar struktur lignin sehingga dapat terurai dan didapatkan selulosa hasil delignifikasi. Berikut adalah spektra dari adosorben daun kelapa, daun kelapa terdelignifikasi, dan selulosa murni.

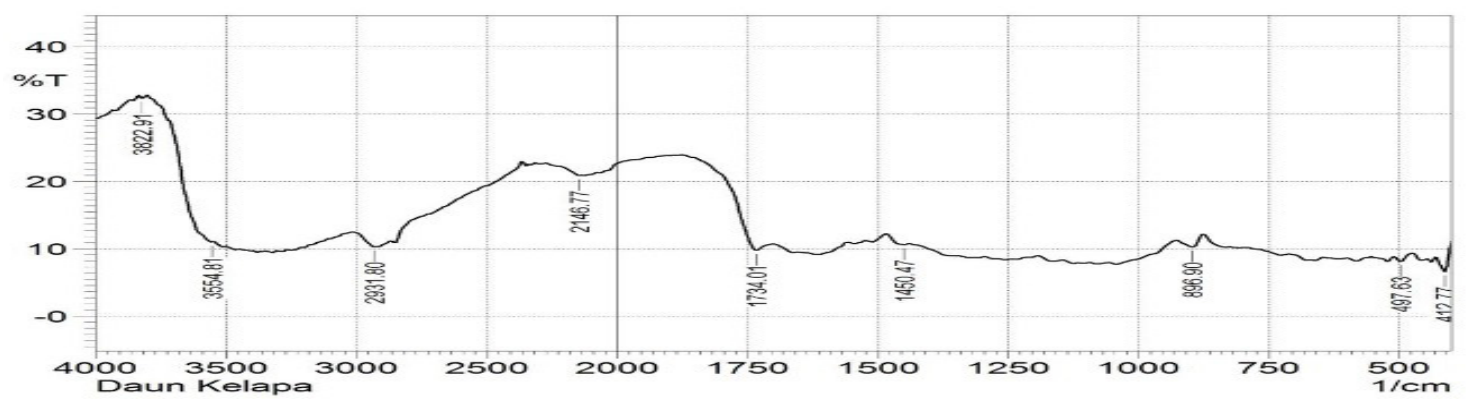

(a)

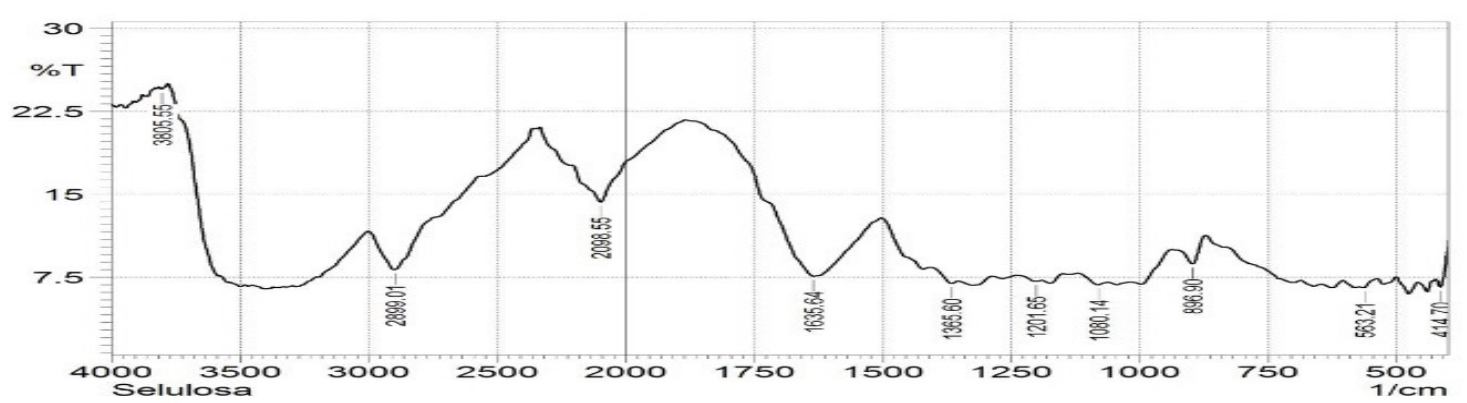

(b) 


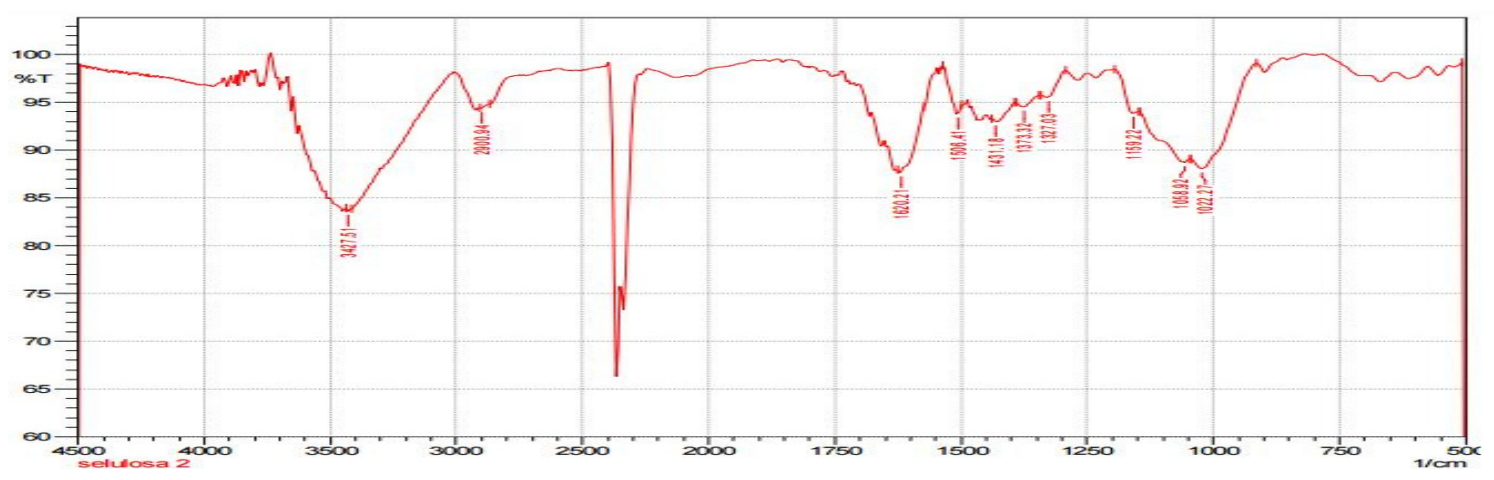

(c)

Gambar 1. Spektra FTIR (a) daun kelapa; (b) selulosa hasil delignifikasi; dan (c) selulosa murni

\section{Isoterm Adsorpsi dan Kondisi Optimum Adsorben}

Untuk mendapatkan tipe isoterm adsorpsi yang menjabarkan hubungan konsentrasi zat warna tekstil Remazol Brilliant Blue dengan jumlah zat warna tekstil Remazol Brilliant Blue yang terserap oleh adsorben, maka dilakukan adsorpsi adsorben daun kelapa dan daun kelapa terdelignifikasi pada variasi konsentrasi zat warna tekstil Remazol Brilliant Blue. Kondisi optimum suatu adsorben adalah kondisi aktivitas adsorben minimum yang memberikan hasil maksimum. Hasil dari penentuan kondisi optimum kedua adsorben ditampilkan pada Tabel 2.

Tabel 2. Pola Isoterm Adsorpsi dan Kondisi Optimum Adsorben

\begin{tabular}{lcc}
\hline & \multicolumn{2}{c}{ Kondisi Optimum } \\
\cline { 2 - 3 } Variabel & $\begin{array}{c}\text { Adsorben } \\
\text { daun } \\
\text { kelapa }\end{array}$ & $\begin{array}{c}\text { Adsorben daun } \\
\text { kelapa } \\
\text { terdelignifikasi }\end{array}$ \\
\hline $\begin{array}{l}\text { Massa } \\
\text { adsorben }\end{array}$ & 0,1 gram & 0,1 gram \\
$\begin{array}{l}\text { Waktu } \\
\text { kontak } \\
\text { pH }\end{array}$ & 15 menit & 15 menit \\
\hline $\begin{array}{l}\text { Jumlah } \\
\text { yang } \\
\text { teradsorpsi }\end{array}$ & $10,6 \mathrm{mg} / \mathrm{g}$ & $10,7 \mathrm{mg} / \mathrm{g}$ \\
\hline $\begin{array}{l}\text { Pola } \\
\text { isoterm } \\
\text { adsorpsi }\end{array}$ & Freundlich & Freundlich \\
\hline
\end{tabular}

Berdasarkan Tabel 2, dapat disimpulkan bahwa semakin banyak massa adsorben yang digunakan untuk menyerap maka semakin jenuh sehingga kemampuan menyerap adsorben menurun. Jumlah adsorben yang ditambahkan ke dalam larutan mempengaruhi efisiensi penyerapan, hal ini sebanding dengan jumlah partikel dan luas permukaan kedua adsorben sehingga menyebabkan sisi aktif adsorpsi dan efisiensi penyerapan meningkat sementara daya serap menurun dengan bertambahnya penambahan adsorben.

Kondisi yang sama ditunjukkan pada pengujian variasi waktu kontak. Semakin lama waktu kontak antara adsorben dan adsorbat maka kemampuan adsorpsi kedua adsorben semakin besar. Hal ini karena adanya waktu kontak yang lama yang memungkinkan semakin banyak terbentuk ikatan antara partikel adsorben dengan zat warna reaktif Remazol Briliant Blue.

Nilai $\mathrm{pH}$ optimum adalah $\mathrm{pH}$ dimana adsorben memiliki kemampuan menyerap adsorbat tertinggi, $\mathrm{pH}$ awal larutan sebelum ditambahkan dengan $\mathrm{NaOH}$ maupun $\mathrm{HCl}$ adalah sebesar 8,9. Berdasarkan hasil yang didapat, diketahui bahwa kedua adsorben memiliki $\mathrm{pH}$ optimum 4 , dengan jumlah yang teradsorpsi $10,6 \mathrm{mg} / \mathrm{g}$ untuk adsorben daun kelapa dan $10,7 \mathrm{mg} / \mathrm{g}$ untuk adsorben daun kelapa terdelignifikasi. $\mathrm{pH}$ memiliki peran penting dalam proses penyerapan, dimana akan terjadi proses interaksi yang berasal dari gugus reaktif zat warna dengan luas permukaan adsorben. Interaksi antara adsorben dan zat warna yang terjadi adalah adsorpsi 
secara fisik (physical adsorption), karena mengikuti pola isoterm adsorpsi Freundlich.

\section{SIMPULAN}

Luas permukaan adsorben daun kelapa dan daun kelapa terdelignifikasi berturut-turut adalah $34,796 \mathrm{~m}^{2} / \mathrm{g}$ dan $31,867 \mathrm{~m}^{2} / \mathrm{g}$. Jumlah situs aktif adalah $29,7258 \times 10^{20} \mathrm{molekul} / \mathrm{gram}$ untuk adsorben daun kelapa dan 28,0522 x $10^{20}$ molekul/gram untuk adsorben daun kelapa terdelignifikasi. Hasil FTIR, adsorben daun kelapa dan daun kelapa terdelignifkasi mengandung gugus $\mathrm{OH}$ dan berikatan hidrogen. Kondisi optimum adsorpsi dari kedua adsorben didapatkan, yaitu $\mathrm{pH} \mathrm{4,} \mathrm{waktu}$ kontak 15 menit, jumlah massa adsorben 0,1 gram, dan mengikuti pola isoterm adsorpsi Freundlich.

\section{UCAPAN TERIMAKASIH}

Pada kesempatan ini penulis mengucapkan terimakasih kepada Kordinator Program Studi Kimia Universitas Udayana beserta seluruh staf dosen atas dukungan dan masukan dalam penelitian ini.

\section{DAFTAR PUSTAKA}

Bernasconi, G., 1995, Teknologi Kimia 2, Jakarta: Pradnya Paramita.

Dewi, M.A.K, 2015, Fotodegradasi Zat Warna Remazol Brilliant Blue Dengan Bentonit Terpilar Fe2O3. Jurnal Kimia,Unud, Bukit Jimbaran.

Fengel, D. dan Wegener, G. 1995, Kayu: Kimia, Ultrastruktur, Reaksi-reaksi, Yogyakarta: UGM-Press.
Fessenden, R.J. and Fessenden, J.S., 1995, Kimia Organik, edisi 3, jilid 2, Jakarta: Erlangga.

Kusumaningtyas, N., 2005, Kemampuan Adsorpsi Tanah Diatomae Hasil Aktivasi dengan Asam Klorida terhadap Zat Warna Tekstil. Jurnal Kimia, Semarang: FMIPA UNNES.

Mahmoud, A. S., 2007, Influence of Temperature and $\mathrm{pH}$ on the Stability and Colorimetric Measurement of Textile Dyes, American Journal of Biotechnology and Biochemistry, Vol 3, 33-41.

Nurwendi, H., Simpen, IN., dan Negara, IM.S., 2016, Sintesis dan Karakterisasi Komposit Selulosa Serbuk Gergaji-Limbah Plastik LDPE (Low Density Polyethylene) dengan Reagen Fenton (H2O2/Fe3+) Sebagai Agen Pengkopling. Jurnal Kimia, 10(1), 89-95.

Sastrohamidjojo, H. 1999. Spektrometri $U V$ Vis. FMIPA UGM: Yogyakarta

Sjostrom, E., 1995, Kimia Kayu, Dasar-dasar dan Penggunaan, edisi kedua, UGMPress. Yogyakarta.

Underwood, A.L. and Day, R.A., 1989, Analisa Kimia Kuantitatif., a.b Pudjaatmaka, H.A., Erlangga. Jakarta.

Windasari, R., 2009, Adsorpsi Zat Warna Tekstil Direct Blue 86 Oleh Kulit Kacang Tanah, Jurnal, UNNES: Semarang.

Wittaya, T., 2009, Microcomposites of Rice Starch Film Reinforced With Microcrystalline Cellulose From Palm Pressed Fiber, International Food Research Journal, 16: 493500. 